\title{
Testicular cytology by fine needle aspiration in domestic cats
}

\author{
D.P. Leme ${ }^{\mathrm{a}}{ }^{*}$, E. Visacre ${ }^{\mathrm{b}}$, V.B. Castro ${ }^{\mathrm{c}}$, M.D. Lopes ${ }^{\mathrm{d}}$ \\ ${ }^{a}$ Department of Rural Development and Animal Sciences, LETA, CCA, Federal University of Santa Catarina, SC, Florianópolis, Brazil \\ ${ }^{\mathrm{b}}$ Veterinary Hospital-UNIP, Bauru, SP, Brazil \\ c Center for Agrarian, Environmental and Biological Sciences, Federal University of Recôncavo da Bahia, Cruz das Almas, BA, Brazil \\ ${ }^{\mathrm{d}}$ Department of Animal Reproduction and Veterinary Radiology, FMVZ, UNESP, Botucatu, SP, Brazil
}

\section{A R T I C L E I N F O}

\section{Article history:}

Received 28 March 2017

Received in revised form

6 October 2017

Accepted 7 October 2017

Available online 9 October 2017

\section{Keywords:}

FNA

Imprint

Testes

Feline

Spermatogenesis

\begin{abstract}
A B S T R A C T
In cases where semen collection in tom-cats is not possible, FNA of testes is the alternative to evaluate sperm production. Although this technique for the diagnosis of fertility problems has been well discussed in other mammals (men, dogs, stallions), data for domestic cats are limited. Therefore, the aim of this study was to verify the reliability of FNA using needles of small diameters (22G and 29G) in testes of domestic cats of different ages to assess the spermatogenesis status and to present description of germ cells and Sertoli cells for cytological examinations. Thirty-four mixed breed cats aged between four months and two years presented for neutering to a Veterinary Hospital were used in this study. Under general anesthesia, testicular measures and FNA were followed by orchiectomy and imprints of the parenchyma of testes and epididymides. Cats were assigned into 3 groups: (G1) 10 cats aged less than 6 months, (G2) 14 cats aged between 6 months and one year and (G3) 10 cats aged more than one year. Cats weighted between 1.5 and $6.0 \mathrm{~kg}$. The mean testicular volume (TV $\mathrm{cm}^{3}$ ) was 0.55 (G1), $1.18(\mathrm{G} 2)$ and 2.66 (G3). Hemorrhages in the needle path were observed in more than $70 \%$ of testes. Few samples (4/68) were excluded due to blood contamination. All germ cells and Sertoli cells were identified and quantified in imprint and FNA smears. Incomplete spermatogenesis was observed in cats aged less than 6 months using both techniques (FNA and imprint); therefore, testicular FNA should not be recommended for cats at this age. Complete spermatogenesis was found in $64 \%$ of cats aged from 6 months up to one year and in all cats aged more than one year. There were no differences of Sertoli cell Index (SEI) and Spermatic Index (SI) between FNA and imprints of cats older than 6 months. In conclusion, FNA using needles of small diameter in the testes of domestic cats is viable, reliable and can be used as a tool for the analysis of the spermatogenesis status of cats older than 6 months, mainly in cases in which semen collection is not possible.
\end{abstract}

() 2017 Elsevier Inc. All rights reserved.

\section{Introduction}

Since testicular fine needle aspiration (FNA) was first described by Posner in 1905 [1], the applicability of this technique in men has been widely discussed to help in the diagnosis of fertility problems [2-6]. More recently, important studies have been carried out in other mammals like equine, canine and feline to elucidate and standardize the use of testicular FNA for the same purpose [7-14].

The first description of testicular FNA in small animals presented a detailed discussion of the technique and its use in cases of

\footnotetext{
* Corresponding author. DZDR, CCA-UFSC, Rodovia Admar Gonzaga, 1346, 88034001, Florianópolis, Brazil.

E-mail address: denise.leme@ufsc.br (D.P. Leme).
}

infertility in dogs [7]. The authors pointed out that cytological examination must be performed after proper anamnesis, testicular palpation and semen analysis; in addition, they confirmed that testicular FNA results were well correlated with histological findings. In other study [8], in addition to clinical exam and semen analysis, testicular volume carried out before testicular FNA provided valuable information about the spermatogenesis of four male dogs.

Testicular FNA is not only a valuable and effective tool for male reproductive evaluation, but also for the choice of a proper therapy. Based on the findings of testicular FNA, it was possible to treat and recover normal ejaculation of an azoospermic dog [9].

Although previous studies have discussed about testicular FNA technique in veterinary medicine [7-16], the detailed description of cells in testicular cytology specimens was only published later by 
Santos et al. [10] and Leme and Papa [11,16] for dogs and horses, respectively.

Testicular FNA in tom-cats is a viable alternative to evaluate sperm production when semen collection is not possible [14]. In feline, testicular FNA was first described in the reproductive evaluation of three jaguars with increased number of abnormal spermatozoa through semen analysis [12]. In these cases, FNA cytology of testes was useful in identifying abnormal binuclear late spermatids. Other results have shown a close relationship between semen and cytological findings.

The evaluation of spermatogenesis using FNA is based on the presence and quantification of germ cells and Sertoli cells $[2,7,16]$. Basically, Sertoli cells have been considered a stable population and in relatively constant number per length unit in the seminiferous tubules of different species, as well as in cats [17-20]. Therefore, the number of Sertoli cells with respect to one hundred germ cells counted in testicular FNA smears has been used as an index (Sertoli cell index-SEI). This index estimates the spermatogenesis potential. Also, the percentage of spermatozoa per one hundred germ cells (Spermatic index- SI) in testicular FNA smears has been related to the ultimate spermatozoa production $[9,10,20]$.

In cases of reproductive evaluation or for assisted reproduction, the testes of tom-cats can be considered small for testicular FNA technique; however, a detailed study about the impact of the testicular fine needle punctures concluded that testicular FNA in tom-cats should be considered a safe procedure [14].

In order to contribute to the standardization of testicular FNA in tom-cats, the aim of this study was to present a detailed description of the technique and the characteristics of germ cells and Sertoli cells in smears of tom-cats of different ages.

\section{Materials and methods}

Experimental procedures were performed in accordance with the Institutional Ethics Committee of School of Veterinary Medicine and Animal Science (FMVZ), São Paulo State University (UNESP), concerning the protection of animals used in scientific experimentation. Thirty-four mixed breed cats aged between 4 months and 2 years presented as patients for neutering to the Veterinary Hospital of FMVZ-UNESP, Botucatu, São Paulo, Brazil, were used in this study. Cats weighted between 1.5 and $6.0 \mathrm{~kg}$. Based on age, animals were assigned into three groups: (G1) 10 cats aged less than 6 months, (G2) 14 cats aged between 6 months and one year and (G3) 10 cats aged more than one year. Only cats considered healthy by clinical and laboratorial preoperative examinations were included.

\subsection{Anesthesia}

Food and water were removed from cats for $12 \mathrm{~h}$ and $2 \mathrm{~h}$, respectively, before anesthesia. General anesthesia was induced with a combination of ketamine hydrochloride (Dopalen ${ }^{\circledR}$, Vetbrands do Brasil, Paulínia, Brazil; $15 \mathrm{mg} / \mathrm{kg}$; im) and xylazine hydrochloride (Xilazin ${ }^{\circledR}$, Syntec do Brasil, Cotia, Brazil; $1 \mathrm{mg} / \mathrm{kg}$; im). Anesthesia was maintained with halothane (Tanohalo ${ }^{\circledR}$, Cristália, Itapira, Brazil) for testicular measurements, FNA procedures of testes and orchiectomy. Cats recovered from anesthesia after orchiectomy in a separated room and were conducted by owners for advised post-operatory at home.

\subsection{Testicular size}

Both testes were measured using a graduated caliper in order to obtain testicular size. Length, width and height measures were recorded and then used to calculate testicular volume using the following formula of an ellipsoid: $4 / 3 \pi \mathrm{x}$ (length/2) $\mathrm{x}$ (width/2) $\mathrm{x}$ (height/2). The volumes of both testes for each cat were combined.

\subsection{Testicular FNA technique}

Scrotum skin was made aseptic before punctures. The testis was firmly held against the scrotum by the gloved hand of the

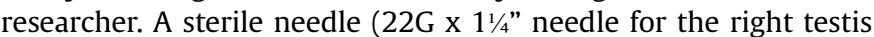
and a $29 \mathrm{G} \times 1 / 2^{\prime \prime}$ needle for the left testis) connected to a $10 \mathrm{~mL}$ syringe (BD SoloMed, Brazil) were used. The needle was gently and perpendicularly advanced from lateral to medial into the parenchyma of testes to avoid blood vessels and the epididymis. After the introduction of the needle tip in the testis, the plunger was pulled half way back to make a vacuum inside the syringe. With the plunger pulled back, the needle was kept within the testis for approximately 3s. This procedure dislodged cells and displaced them into the needle. The plunger was released before withdrawing the needle from the testis. The needle was detached from the syringe to prevent the sample from blood contamination. Digital pressure was immediately applied to the puncture site to promote haemostasis.

A new puncture was immediately performed at a slightly more cranial or caudal site of the same testis when the sample obtained was judged insufficient or presented blood contamination.

The needle containing the material was reattached to the syringe after filling it with air. The plunger was pressed to expel the sample onto a glass slide. The samples obtained from both techniques were classified according to their characteristics (macroscopic and microscopic) immediately observed after sample collection.

The smear was gently prepared, air-dried and stained with fast Diff-Quick (Panotic) (Laborclin, Brazil). Smears were examined using light microscope at magnification of $\times 400$ to $\times 1.250$ for the identification of testicular cells according to Foresta et al. [2,20], Santos et al. [10] and Leme and Papa [11]. Two-hundred germ cells were identified, counted and recorded as the following: spermatogonia, primary spermatocytes, secondary spermatocytes, early spermatids, late spermatids and spermatozoa. Germ cells were expressed as percentages and the percentage of spermatozoa related to the total number of germ cells was expressed as spermatic index (SI) [20]. While counting germ cells, Sertoli cells between them were recorded apart as Sertoli cells/100 germ cells and expressed as Sertoli cell Index (SEI) [20].

\subsection{Examination of the testicular parenchyma}

After conventional orchiectomy, both testes were longitudinally sectioned in order to verify macroscopic parenchyma lesions according to hemorrhage diameter found around the needle path (Fig. 1). Lesions were classified as: fine hemorrhage (diameter less than $5 \mathrm{~mm}$ ), intermediate hemorrhage (diameter between 5 and $10 \mathrm{~mm}$ ) and large hemorrhage (diameter larger than $10 \mathrm{~mm}$ ).

\subsection{Testicular imprint}

Imprints of both testes were carried out after testicular parenchyma examination. A glass slide was gently pressed against the parenchyma surface longitudinally sectioned avoiding the area with hemorrhage. Imprints were air-dried, stained with Diff-Quick (Panotic) (Laborclin, Brazil), examined using light microscope at magnification from $\times 400$ to $\times 1.250$. Identification and quantification of cells from seminiferous epithelium were performed according to Santos et al. [10] and Leme and Papa [11]. Quantification of testicular cells followed the same procedure used in smears of the FNA technique. 


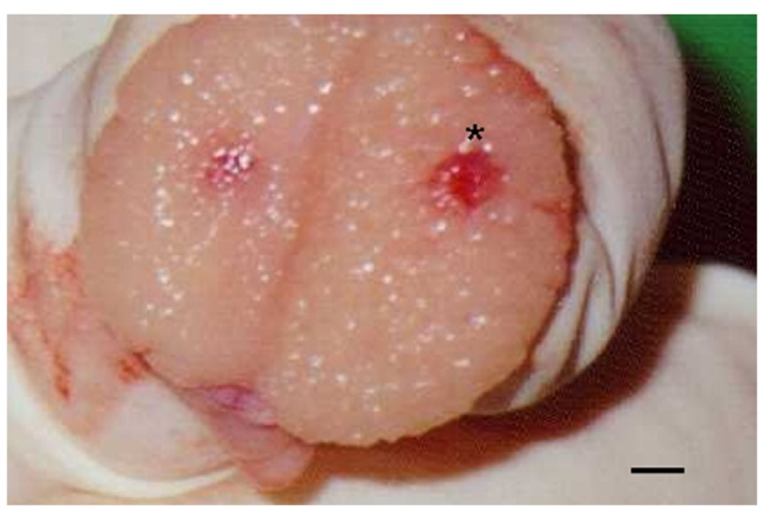

Fig. 1. Hemorrhagic lesions observed in the testicular parenchyma of an adult cat after puncture using a $29 \mathrm{G} \times 1 / 2^{\prime \prime}$ needle. Scale bar indicates $2 \mathrm{~mm}$.

\subsection{Epididymal imprint}

In order to perform epididymal imprint, epididymides from each cat were sectioned and a glass slide was carefully pressed against its cut surface. Imprints were air-dried, stained with the modified Karras method [21] and examined using light microscope at magnification from $\times 400$ to $\times 1.250$. Samples were observed to verify the presence or absence of spermatozoa.

\subsection{Statistical analysis}

The mean value was used as a measure of central tendency and the standard deviation (SD) was used as a measure of variability for the quantification of germ and Sertoli cells in both techniques (FNA and imprints). Samples with no material were scored "zero" and used only for comparisons between techniques. Comparisons between cellularities were performed separately for G2 (cats aged between 6 months and one year) and G3 (cats aged more than one year) for a multiple comparisons test at $\mathrm{p}<0.05$ using General Linear Models (GLM procedure) of the Statistical Analysis Systems Institute (SAS Institute Inc., Cary, NC, USA) [22]. Firstly, imprints between left and right testes were compared in order to verify if both testes in G2 and G3 presented similar proportions of each cell type. Thereafter, the proportions of each cell in the same testis in G2 and G3 were compared between imprint and FNA smears (22G $\mathrm{x}$ $1 \frac{1 / 4}{4}$ needle for the right testis and $29 \mathrm{G} \times 1 / 2$ "needle for the left testis).

\section{Results}

The mean testicular volume ( $\mathrm{TV} \mathrm{cm}^{3}$ ) was 0.55 (G1), 1.18 (G2) and 2.66 (G3). Macroscopic lesions in the testicular parenchyma after needle puncture (22G and 29G) are described in Table 1.

\section{Table 1}

Macroscopic lesions in the testicular parenchyma after needle puncture (22G needle for the right testes and 29G needle for the left testes) found in domestic cats of G1cats aged less than six months $(n=10)$; G2-cats aged between six months and one year $(n=14)$; G3-cats aged more than one year $(n=10)$.

\begin{tabular}{lllllll}
\hline & G1 & & G2 & & G3 \\
\hline Macroscopic lesions & $22 \mathrm{G}$ & $29 \mathrm{G}$ & $22 \mathrm{G}$ & $29 \mathrm{G}$ & $22 \mathrm{G}$ & $29 \mathrm{G}$ \\
No lesions $^{\text {Fine hemorrhage }}$ & $30 \%$ & $30 \%$ & $21 \%$ & $21 \%$ & 0 & $10 \%$ \\
Intermediate hemorrhage $^{\mathrm{a}}$ & $40 \%$ & $40 \%$ & $7 \%$ & $7 \%$ & $20 \%$ & $50 \%$ \\
Circular hemorrhage $^{\mathrm{a}}$ & $20 \%$ & $20 \%$ & $29 \%$ & $29 \%$ & $50 \%$ & $20 \%$ \\
\hline
\end{tabular}

\footnotetext{
${ }^{a}$ Lesions found only in the needle path.
}

To obtain enough material for classification, two attempts of both techniques in each testis were performed. The characteristics and the number of testicular samples for cytological examination obtained by fine needles and imprints in the three groups of domestic cats are shown in Tables 2 and 3.

Imprint and FNA smears had a variety of arrangements of germ cells and Sertoli cells (Fig. 2). Leydig cells were occasionally seen among arrangements only in imprint cytology smears. Erythrocytes and leukocytes were present due to blood contamination of some testicular samples during the performance of techniques (imprint or punctures). Mucus like fluid was occasionally observed between cells and structures. Damaged cells, deformed naked nuclei and cytoplasm fragments were frequent in the background of smears (ranged between 10 and 29\% of 200 consecutive identified germ cells). Unidentified structures and cells that are not part of the seminiferous epithelium were not counted, as described in the methodology of this study.

The different cell types identified on cytological evaluation are depicted in Fig. 3.

Cells with two, three or four nuclei were found and classified according to their morphological and staining characteristics. Giant multinucleated cells were not observed.

Early spermatid was the oldest germ cell type found in only $2 / 10$ cats aged less than 6 months. FNA samples obtained from G1 did not provide enough data for comparing techniques. Quantification of testicular cell types and Sertoli cells in cytological exams obtained by imprints and fine needle aspiration (22G and 29G), performed in G1, G2 and G3 are shown in Tables 4 and 5, respectively.

No spermatozoa were identified in testes and epididymis of cats less than six months old. In cats aged between six months and one year, $64 \%$ presented spermatozoa in testes and 50\%, in epididymis, whereas spermatozoa were present in testes and epididymis of all cats aged more than one year.

\section{Discussion}

FNA has already been used in the testes of dogs with needles sizes 20G [7], 21-23G [9] and 19-23G [13]. It was possible to perform testicular punctures using fine needles of two different sizes, $22 \mathrm{G} \times 1 \frac{1 / 4}{4}$ and $29 \mathrm{G} \times 1 / 2^{\prime \prime}$ needles in cats aged older than 6 months with testicular volumes between 1.18 and $2.66 \mathrm{~cm}^{3}$. Few samples were unviable due to the presence of blood; however, hemorrhages could be observed in more than $70 \%$ of testes, regardless of needle size. The hemorrhages observed in this study were restricted to the path taken by the needle, varying between fine and circular areas (less than $0.5 \mathrm{~cm}$ in diameter), which is in agreement with a previous study also in cats [14]. The impact of FNA on feline testes using 26G needle caused hemorrhagic areas in 20 out of 24 testes observed only during the first post-aspiration week [14].

\section{Table 2}

Characteristics and percentages of suitable samples obtained from testicular fine needle aspiration using $22 \mathrm{G}$ needle for the right testes and 29G needle for the left testes, in domestic cats of G1-cats aged less than six months $(n=10)$; G2-cats aged between six months and one year $(n=14)$; G3-cats aged more than one year $(\mathrm{n}=10)$.

\begin{tabular}{|c|c|c|c|c|c|c|}
\hline & \multicolumn{3}{|c|}{ 22G (Right Testes) } & \multicolumn{3}{|c|}{ 29G (Left Testes) } \\
\hline & G1 & G2 & G3 & G1 & G2 & G3 \\
\hline No material & 40 & 14.3 & 30 & 20 & 21.4 & 0 \\
\hline Blood only & 0 & 0 & 10 & 20 & 10 & 10 \\
\hline Blood and Sertoli cell only & 30 & 14.3 & 0 & 20 & 14.3 & 0 \\
\hline Sertoli cell only & 20 & 14.3 & 0 & 40 & 14.3 & 0 \\
\hline Germ cells and Sertoli cells & 10 & 57.1 & 60 & 0 & 50 & 90 \\
\hline
\end{tabular}


Table 3

Characteristics and number of suitable samples obtained from testicular imprint cytology in domestic cats of G1-cats aged less than six months $(n=10)$; G2-cats aged between six months and one year $(n=14)$; G3-cats aged more than one year $(\mathrm{n}=10)$.

\begin{tabular}{llllllll}
\hline & \multicolumn{3}{l}{ Imprint Right Testes } & & \multicolumn{2}{l}{ Imprint Left Testes } \\
\cline { 2 - 3 } & G1 & G2 & G3 & & G1 & G2 & G3 \\
\hline No material & 20 & $0 / 14$ & 0 & & 10 & $0 / 14$ & $0 / 10$ \\
Blood only & 0 & $0 / 14$ & 0 & & 0 & $0 / 14$ & $0 / 10$ \\
Blood and Sertoli cell only & 30 & 14.3 & 0 & & 50 & $0 / 14$ & $0 / 10$ \\
Sertoli cell only & $0 / 10$ & 14.3 & 0 & & 20 & 21.4 & $0 / 10$ \\
Germ cells and Sertoli cells & $50^{\mathrm{a}}$ & 71.4 & 100 & & $20^{\mathrm{b}}$ & 78.6 & $10 / 10$
\end{tabular}

a Spermatogonia only.

b Spermatogonia to early spermatids.

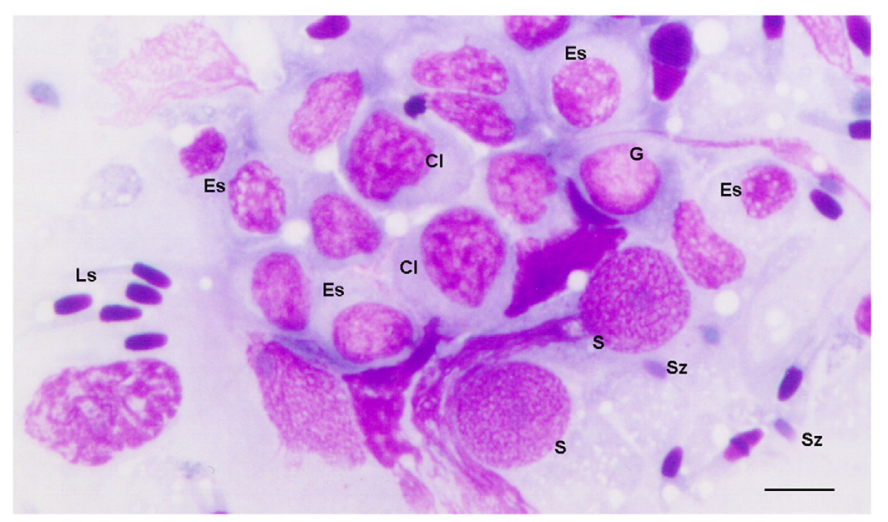

Fig. 2. Testicular FNA cytology of an adult tom cat with normal spermatogenesis. Spermatogonium $(\mathrm{G})$, primary spematocytes $(\mathrm{CI})$, Early spermatids (Es), late spermatids (Ls), spermatozoa (Sz), Sertoli cells (S) in a Diff-Quick-stained smear using light microscopy. Scale bar indicates $10 \mu$.

Further studies are necessary to verify the consequences of testicular FNA in the sperm production of cats, mainly in cases that testicular FNA is used in addition to semen evaluation. Testicular FNA has proven to be safe for sperm production in dogs, horses and men $[7,11,13,20]$.

Morphologic characteristics of testicular cells were similar by imprint cytology and FNA, except for Leydig cells, which were observed only in imprints. It is possible that Leydig cells are not observed in FNA smears due to the fact that their cytoplasms full of vacuoles [10] were damage as a result of aspiration or smear processes, or because they were strongly attached to the interstitium. In a previous study, the identification of spermatogenic cells, Sertoli cells and Leydig cells of dogs in testicular imprints showed the possibility of extending such results to FNA [10]. Other studies have used imprint cytology with success as control of FNA cytology in men and alpacas $[23,24]$. In this study, the morphologic and staining characteristics of testicular cells were similar to those described in dogs, stallions and men $[2,10,11,20,25]$. There were no specific findings that could differentiate characteristics of the testicular cells of domestic cats from other mammals already studied.

In this study, no spermatozoa were identified in cats less than six months old in examinations performed in both FNA and testicular imprints and in imprints of the epididymides [26,27]. This probably occurred because, at this age, seminiferous tubules present only one cell layer and few tubules have tubular lumina [26]. Once cats aged less than six months probably presented incomplete spermatogenesis, testicular FNA for spermatogenesis analysis should not be recommended for cats at this age.
On the other hand, in domestic cats aged over six months, testicular FNA proved to be a feasible and effective technique; not only for providing enough samples for cytology of testes, but also for being minimally invasive [14].

A complete spermatogenesis was observed in $64 \%$ of cats aged from six months up to one year by both imprint and FNA, which could be confirmed by the presence of epididymal sperm [26,27]. In these cats, there were no quantitative differences between imprint and FNA cytology (using both needles); therefore, FNA provided representative samples of the spermatogenesis status and can be used for this purpose. All cats older than one year presented complete spermatogenesis observed by both techniques (Imprint and FNA) [26,27]. permatozoa and Sertoli cells indexes were not different between techniques or between FNA using 22G or 29G needles when performed in cats older than 6 months. Since SEI and SI represent the potential and efficiency of spermatogenesis $[9,10,20,23]$, these results confirm that testicular FNA is suitable for spermatogenesis analysis in adult cats [14].

The small percentages of secondary spermatocyte presented in this study were also observed in other species and can be explained by its short life span $[3,11,20]$. Similar germ cell percentages found in imprints and FNA smears of cat aged between six months and one year were also observed in other mammals, including men [3,8-11,20]. Percentages of sparmatogonia, primary spermatocytes and spermatids were different between imprints and FNA smears only in cats older than one year. The cause for these differences between techniques in adult cats is unknown. Sometimes it may be difficult to differentiate spermatogonia from primary spermatocytes [25]. For spermatids, the differences between techniques may have occurred because these cells were generally observed in groups with different numbers, and heterogeneously distributed in the glass slide. In alpacas [24], quantitative differences were observed in Sertoli cell index (SEI) between testicular FNA and imprint smears, which may have been a result of the preparation process. In this study, we found unidentifiable structures in the background of the slide that may be cells rupture during sample preparation. Nevertheless, both techniques presented increasing percentages from spermatogonia to spermatids corresponding to the progression of germinative cell maturation through spermatogenesis, and no difference was observed in SEI and SI values between techniques. Therefore, the interference of ruptured cells was somewhat less probable, since there were no differences in SEI and SI between the techniques used in this study.

Performing and interpreting testicular FNA requires training and special care in the different stages: delicate aspiration of the testes, gentle preparation of smears and detailed description of the cellular characteristics. Training is also critical to identify the germ cells according to the stage of spermatogenesis or the possible amount of ruptured and unclassifiable cells, as well as for accessing the testes without causing lesions. It is important to emphasize that the more mature the spermatogenic cells, the better preserved they will be [25] and, although Sertoli cells are easily broken, their nuclei are easily identifiable $[2,20,25]$. Thus, an immediate result of the testicular FNA would be given by the presence of spermatozoa in the smears showing that the spermatogenesis is complete. On the other hand, differential counting of germ cells and Sertoli cells to calculate the proportions and the numeric relationships between spermatogenic cells and Sertoli cells (SEI) had already been described as an important tool to the diagnosis and therapy of azoospermic and olizoospermic dogs [9] and men [2,3], and of a case of transitory testicular degeneration in a stallion [28].

The lack of information about tubular diameter, basement membrane, seminiferous epithelium architecture and interstitial tissue are limitations of the imprint and FNA techniques [7,25] when compared to testicular biopsy. Although there were 


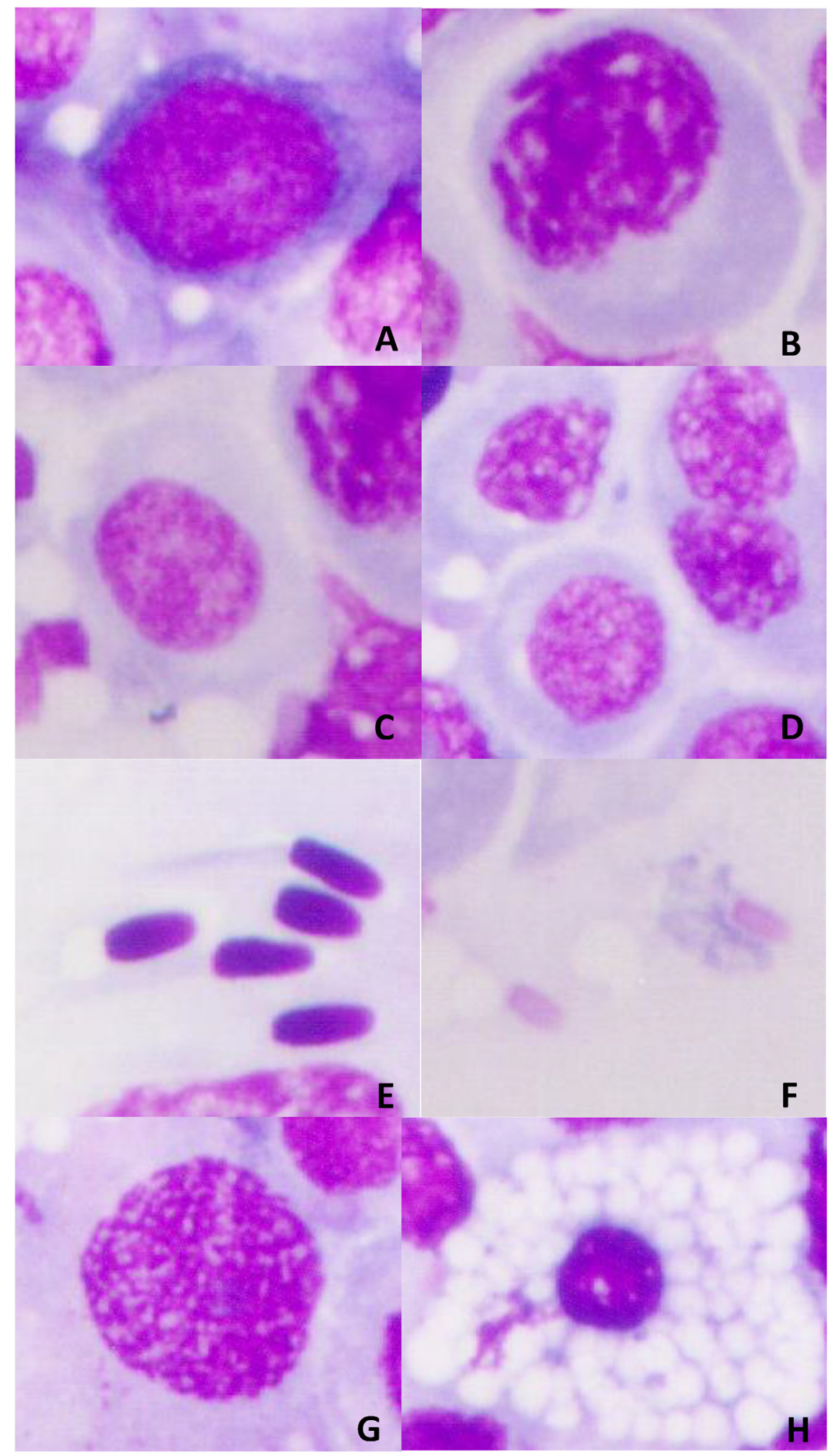

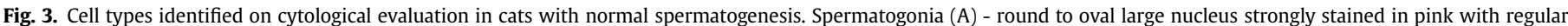

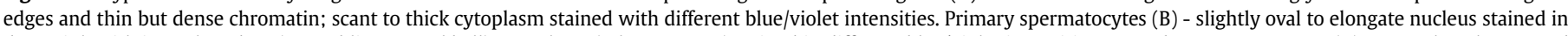

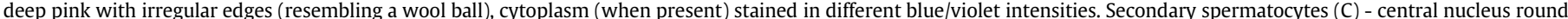

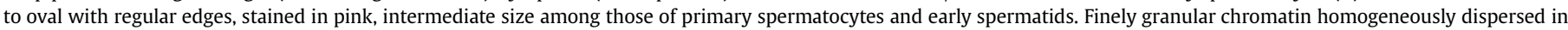

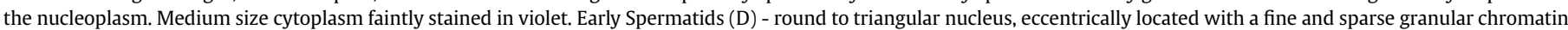

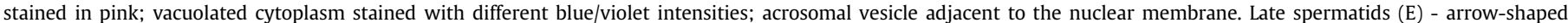

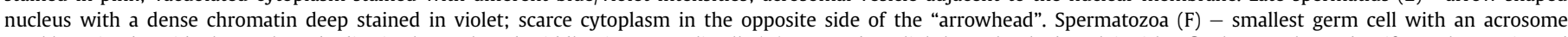

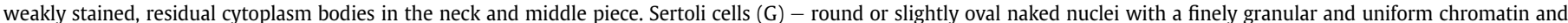

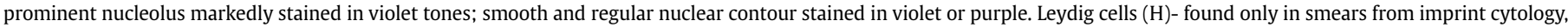

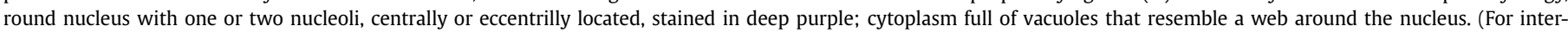
pretation of the references to colour in this figure legend, the reader is referred to the web version of this article.) 
Table 4

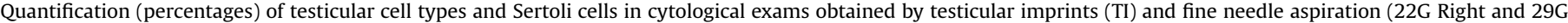
Left), performed in domestic cats aged between six months and one year (G2, n =14).

\begin{tabular}{|c|c|c|c|c|c|c|c|}
\hline \multirow[t]{3}{*}{ Cell types (\%) } & \multirow{2}{*}{$\frac{\mathrm{A}}{\text { TI Right }(\mathrm{N}=10)}$} & \multirow{2}{*}{$\frac{\mathrm{B}}{\mathrm{TI} \text { Left }\left({ }^{\mathrm{a}} \mathrm{N}=10 / 11\right)}$} & \multirow{2}{*}{$\frac{\mathrm{C}}{22 \mathrm{G} \text { Right }(\mathrm{N}=10)}$} & \multirow{2}{*}{$\frac{\mathrm{D}}{29 \mathrm{G} \text { Left }(\mathrm{n}=7)}$} & \multirow{2}{*}{$\frac{\mathrm{A} \times \mathrm{B}}{\text { TI Right } \mathrm{x} \text { TI Left }}$} & \multirow{2}{*}{$\frac{\mathrm{A} \times \mathrm{C}}{\text { TI Right } \times 22 \mathrm{G} \text { Right }}$} & \multirow{2}{*}{$\frac{\text { B x D }}{\text { TI Left x 29G Left }}$} \\
\hline & & & & & & & \\
\hline & Mean \pm SD & Mean \pm SD & Mean \pm SD & Mean \pm SD & $P$ value & $P$ value & $P$ value \\
\hline Spermatogonia & $4.10 \pm 2.07$ & $4.50 \pm 4.69$ & $2.94 \pm 1.97$ & $1.78 \pm 1.49$ & 0.80 & 0.07 & 0.16 \\
\hline Primary spermatocytes & $10.15 \pm 3.94$ & $16.54 \pm 22.47$ & $10.00 \pm 6.55$ & $7.00 \pm 5,46$ & 0.38 & 0.41 & 0.29 \\
\hline Secondary spermatocytes & $0.25 \pm 0.35$ & $0.40 \pm 0.56$ & $0.13 \pm 0.35$ & $0.21 \pm 0.56$ & 0.48 & 0.33 & 0.51 \\
\hline Early spermatid & $43.75 \pm 15.76$ & $44.80 \pm 11.41$ & $44.75 \pm 10.51$ & $38.00 \pm 12.05$ & 0.86 & 0.35 & 0.25 \\
\hline Final spermatid & $27.50 \pm 11.35$ & $29.90 \pm 11.51$ & $30.75 \pm 10.75$ & $41.50 \pm 14.40$ & 0.64 & 0.64 & 0.08 \\
\hline Spermatozoa index (SI) & $14.25 \pm 12.57$ & $11.75 \pm 9.91$ & $11.44 \pm 9.48$ & $11.5 \pm 8.59$ & 0.62 & 0.32 & 0.95 \\
\hline Sertoli cell index (SEI) & $5.9 \pm 3.39$ & $10.65 \pm 10.24$ & $8.63 \pm 4.13$ & $7.07 \pm 3.77$ & 0.18 & 0.61 & 0.39 \\
\hline
\end{tabular}

${ }^{a} \mathrm{~N}=11$ (spermatogonia, primary spermatocytes, final spermatids); $\mathrm{N}=10$ (secondary spermatocytes, early spermatids, spermatozoa, Sertoli cell).

Table 5

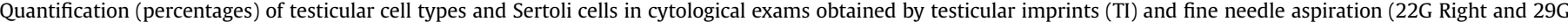
Left), performed in domestic cats aged more than one year $(G 3, n=10)$.

\begin{tabular}{|c|c|c|c|c|c|c|c|}
\hline \multirow[t]{3}{*}{ Cell types (\%) } & \multirow{2}{*}{$\frac{\mathrm{A}}{\text { TI Right }(\mathrm{N}=10)}$} & \multirow{2}{*}{$\begin{array}{l}\mathrm{B} \\
\text { TI Left }(\mathrm{N}=10) \\
\end{array}$} & \multirow{2}{*}{$\begin{array}{l}\mathrm{C} \\
22 \mathrm{G} \text { Right }\left({ }^{\mathrm{a}} \mathrm{N}=10 / 9\right)\end{array}$} & \multirow{2}{*}{$\begin{array}{l}\mathrm{D} \\
29 \mathrm{G} \text { Left }(\mathrm{N}=9) \\
\end{array}$} & \multirow{2}{*}{$\begin{array}{l}\text { A x B } \\
\text { TI Right x TI Left } \\
\end{array}$} & \multirow{2}{*}{$\frac{\mathrm{A} \times \mathrm{C}}{\text { TI Right } \times 22 \mathrm{G} \text { Right }}$} & \multirow{2}{*}{$\frac{\text { B x D }}{\text { TI Left x 29G Left }}$} \\
\hline & & & & & & & \\
\hline & Mean \pm SD & Mean \pm SD & Mean \pm SD & Mean \pm SD & $P$ value & $P$ value & $P$ value \\
\hline Spermatogonia & $3.45 \pm 1.90$ & $2.80 \pm 1.88$ & $2.20 \pm 0.95$ & $2.83 \pm 1.88$ & 0.45 & 0.005 & 0.96 \\
\hline Primary spermatocytes & $6.90 \pm 4.20$ & $7.35 \pm 2.79$ & $6.33 \pm 3.78$ & $3.77 \pm 3.00$ & 0.78 & 0.12 & 0.01 \\
\hline Secondary spermatocytes & $0.60 \pm 0.46$ & $0.60 \pm 0.61$ & $0.75 \pm 0.69$ & $0.33 \pm 0.55$ & 1.00 & 0.55 & 0.33 \\
\hline Early spermatid & $43.40 \pm 9.07$ & $46.70 \pm 8.18$ & $37.33 \pm 8.64$ & $33.05 \pm 16.34$ & 0.40 & 0.01 & 0.03 \\
\hline Final spermatid & $31.95 \pm 11.46$ & $26.60 \pm 11.96$ & $43.50 \pm 17.68$ & $48.11 \pm 17.94$ & 0.32 & 0.74 & 0.006 \\
\hline Spermatozoa index (SI) & $13.7 \pm 8.37$ & $15.95 \pm 6.93$ & $10.08 \pm 6.76$ & $11.88 \pm 12.75$ & 0.52 & 0.07 & 0.39 \\
\hline Sertoli cell index (SEI) & $3.45 \pm 1.89$ & $5.00 \pm 3.51$ & $7.67 \pm 4.99$ & $8.72 \pm 5.12$ & 0.23 & 0.38 & 0.08 \\
\hline
\end{tabular}

${ }^{a} \mathrm{~N}=10$ (spermatogonia, primary spermatocytes, secondary spermatocytes); $\mathrm{N}=9$ (early spermatids, final spermatids, spermatozoa, Sertoli cell).

differences between those techniques, the results regarding spermatogenesis function are equivalent between them, histological versus cytological evaluations (imprint or FNA), and imprint versus FNA, as observed in this study $[2-7,24,25]$.

In cats aged more than one year SI and SEI were lower than those estimated for dogs [9,10], which were already considered lower than those of stallions and men $[9,11,20]$. This result is in agreement with a study in which Sertoli cells in domestic cats were considered the least efficient among mammals and the spermatogenesis efficiency in this species was described as moderate [19].

According to our objectives, we presented results of normal testes of cats over six months of age, obtained through imprints and FNA (22G and 29G). Moreover, the present study showed that FNA using needles of small diameter in the testes of domestic cats is viable, reliable and can be used as a tool for the analysis of the spermatogenesis status in this species, mainly in cases in which semen collection is not possible. However, testicular FNA should be used only in domestic cats older than six months.

\section{Acknowledgements}

The authors are grateful to Ricardo Martins Bernardes for helping with the statistical analysis, to the Department of Animal Reproduction and Veterinary Radiology, FMVZ, UNESP. Erika Visacre de Carvalho was supported by PIBIC/CNPq.

\section{References}

[1] Posner C. Die diagnostische hodenpunktion. Berl Klin Wochenschr 1905;24: $1119-21$.

[2] Foresta C, Varotto A, Scandellari C. Assessment of testicular cytology by fine needle aspiration as a diagnostic parameter in the evaluation of the azoospermic subject. Fertil Steril 1992;57:858-65.

[3] Foresta C, Varotto A. Assessment of testicular cytology by fine needle aspiration as a diagnostic parameter in the evaluation of the oligospermic subject. Fertil Steril 1992;58:1028-33.

[4] Odabas Ö, Ugras S, Aydin S, Yilmaz Y, Kemal Atilla M. Assessment of testicular cytology by fine-needle aspiration and the imprint technique: are they reliable diagnostic modalities? Brit J Urol 1997;79:445-8.

[5] Batra VV, Khadgawat R, Agarwal A, Krishnani N, Mishra SK, Mithal A et al. Correlation of cell counts and indices in testicular FNAC with histology in male infertility. Acta Cytol 1999;43:617-23.

[6] Qublan HS, Al-Jader KM, Al-Kaisi NS, Alghoweri AS, Abu-Khait SA, AbuQamar AA, et al. Fine needle aspiration cytology compared with open biopsy histology for the diagnosis of azoospermia. J Obstet Gynaecol 2002;22: 527-31.

[7] Dhalbom M, Mäkinen A, Suominen J. Testicular fine needle aspiration cytology as a diagnostic tool in dog infertility. J Small Anim Pract 1997;38:506-12.

[8] De Souza FF, Leme DP, Uechi E, Trinca LA, Lopes MD. Evaluation of testicular fine needle aspiration cytology and serum testosterone levels in dogs. Braz J Vet Res Anim Sci 2004;41:98-105.

[9] Romagnoli S, Bonaccini P, Stelletta C, Garolla A, Menegazzo M, Foresta C, et al. Clinical use of testicular fine needle aspiration cytology in oligozoospermic and azoospermic dogs. Reprod Domest Anim 2009;44:329-33.

[10] Santos M, Marcos R, Caniatti M. Cytologic study of normal canine testis. Theriogenology 2010;73:208-14.

[11] Leme DP, Papa FO. Cytological identification and quantification of testicular cell types using fine needle aspiration in horses. Equine Vet J 2000;32:444-6.

[12] Paz RCRD, Leme DP, Züge RM, Pessuti C, Santos EF,Barnabe RC. Testicular fine needle aspiration cytology as a diagnostic tool in jaguar (Panthera onca) infertility. Braz J Vet Res Anim Sci 2003:40:100-7.

[13] Gouletsou PG, Galatos AD, Leontides LS, Sideri AI. Impact of fine - or largeneedle aspiration on canine testes: clinical, in vivo ultrasonographic and seminological assessment. Reprod Dom Anim 2011;46:712-9.

[14] Gouletsou PG, Galatos AD, Sideri AI, Kostoulas P. Impact of fine needle aspiration (FNA) and of the number of punctures on the feline testis: clinical, gross anatomy and histological assessment. Theriogenology 2012;78:172-81.

[15] Gouletsou PG, Galatos AD, Leontides LS, Sideri AI. Impact of fine or large needle aspiration on the dog's testis: in vitro ultrasonographic, bacteriological, gross anatomy and histological assessment. Theriogenology 2010;74: $1604-14$.

[16] Leme DP, Papa FO. How to perform and interpret testicular fine needle aspiration in stallions. J Equine Vet Sci 2010;30:590-6.

[17] Hochereau-de Reviers MT, Monthsnet-Kuntz C, Courot M. Spermatogenesis and Sertoli cell numbers and function in rams and bulls. J Rep Fer S 1986;34: 101-14.

[18] Griswold MD. The central role of Sertoli cells in spermatogenesis. 1988. 
[19] França LR, Godinho CL. Testis morphometry, seminiferous epithelium cycle length, and daily sperm production in domestic cats (Felis catus). Biol Reprod 2003;68:1554-61.

[20] Foresta C. Citologia testicolare per agoaspirazione nella diagnostica dell'infertilità maschile. Piccin 1993:152.

[21] Papa FO, Alvarenga MA, Bicudo SD, Lopes MD, Ramires PRN. Coloração espermática segundo Karras modificado pelo emprego do Barbatimão (Sthyphnodendrum barbatiman). Arq Bras Med Vet Zoo 1988;40:115-23.

[22] SAS Institute Inc., Cary, NC, USA, 1990.

[23] Papić Z, Katona G, Skrabalo Z. The cytologic identification and quantification of testicular cell subtypes. Reproducibility and relation to histologic findings in the diagnosis of male infertility. Acta Cytol 1987;32:697-706.

[24] Stelletta C, Juyena NS, Salazar DP, Ruiz J, Gutierrez G. Testicular cytology of alpaca: comparison between impressed and smeared slides. Anim Reprod Sc 2011;125:133-7.

[25] Schenck U, Schill WB. Cytology of the human seminiferous epithelium. Acta Cytol 1987;32:689-96.

[26] Siemieniuch MJ, Woclawek-Potocka I. Morphological features of the seminiferous epithelium in cat (Felis catus, L. 1758) testes. J Reprod Dev 2007;53: $1125-30$.

[27] Tsutsui T, Kuwabara S, Kuwabara K, Kugota Y, Kinjo T, Hori T. Development of spermatogenic function in the sex maturation process in male cats. J Vet Med Sci 2004;66:1125-7.

[28] Papa FO, Leme DP. Testicular fine needle aspiration cytology from a stallion with testicular degeneration after external genitalia trauma. J Eq Vet Sc 2002;22:121-4. 